\title{
Doege-Potter Syndrome, cause of nonislet cell tumor hypoglycemia: the first case report from Nepal
}

This article was published in the following Dove Press journal:

International Medical Case Reports Journal

16 August 2017

Number of times this article has been viewed

\author{
Vivek Pant' \\ Suman Baral ${ }^{2}$ \\ Gita Sayami ${ }^{3}$ \\ Prakash Sayami ${ }^{4}$ \\ 'Department of Biochemistry, \\ ${ }^{2}$ Endocrinology Unit, Department of \\ Medicine, ${ }^{3}$ Department of Pathology, \\ ${ }^{4}$ Manmohan Cardiothoracic vascular \\ and transplant Center, Institute \\ of Medicine (IOM), Tribhuvan \\ University Teaching Hospital (TUTH), \\ Kathmandu, Nepal
}

\begin{abstract}
Doege-Potter syndrome (DPS), a paraneoplastic syndrome, presents as a hypoinsulinemic hypoglycemia from the ectopic secretion of insulin-like growth factor II from a solitary fibrous tumor which may be intrapleural or extrapleural in origin. We report a case of severe hypoglycemia in a 70-year old female initially admitted for resection of left sided solitary fibrous tumor of pleura. Investigation revealed true hypoglycemia, and DPS was diagnosed. The tumor was completely resected, after which no further hypoglycemic episodes were seen in 2 years follow-up. This is the first case of solitary fibrous tumor of pleura with DPS reported from Nepal. Keywords: insulin-like growth factor II, IGF-II, solitary fibrous tumor, hypoglycemia
\end{abstract}

\section{Case report}

A 68-year-old female was found lying unconscious at her home and was brought to the emergency department. She had previous history of acute mental confusion, evolving to unconsciousness. No significant past medical, surgical or social history was found. On admission, physical examination showed only signs related to pleural effusion on the left side. There was hypotension (blood pressure $-90 / 60 \mathrm{mmHg}$ ), and pulse was normal. With the exception of profound hypoglycemia (serum glucose: $23.7 \mathrm{mg} / \mathrm{dL}$ ), laboratory results were normal. After administration of intravenous dextrose solution, she gained consciousness. The chest x-ray revealed a large left sided pleural effusion (Figure 1). On transthoracic puncture, a tumor of pleural origin was diagnosed. On noncontrast computed tomography of the chest, a large heterogeneously enhancing left lung mass with pleural effusion was seen (Figure 2), so ultrasound-guided fine needle aspiration cytology was advised for further diagnosis. The ultrasonographicguided aspiration from the left lung mass showed cytomorphological features favoring spindle cell carcinoid and trucut biopsy was ordered for definite diagnosis. On trucut biopsy, the differential diagnosis of solitary fibrous tumor and spindle cell carcinoid tumor was made, so immunohistochemistry was advised. On immunohistochemistry analysis, the specimen was immunoreactive to BCL-2 and CD34. (Figure 3A and 3B) Chromogranin A and Synaptophysin were nonimmunoreactive. Thus, histopathologic examination along with immunohistochemistry confirmed the diagnosis of a solitary fibrous tumor of pleura (SFTP).

For the treatment of the tumor, the patient was admitted and was considered for surgical resection. The admission prior to surgery was complicated by hypoglycemia, leading to cancellation of the surgery. Surgery was postponed until an endocrinology evaluation was completed. There was absence of any underlying endocrine pathology.
Correspondence: Vivek Pant

Department of Biochemistry, Institute of medicine (IOM), Tribhuvan University Teaching Hospital (TUTH), Maharajgunj Rd, Kathmandu 44600, Nepal

Tel +977984l486789

Email drvpant@gmail.com 


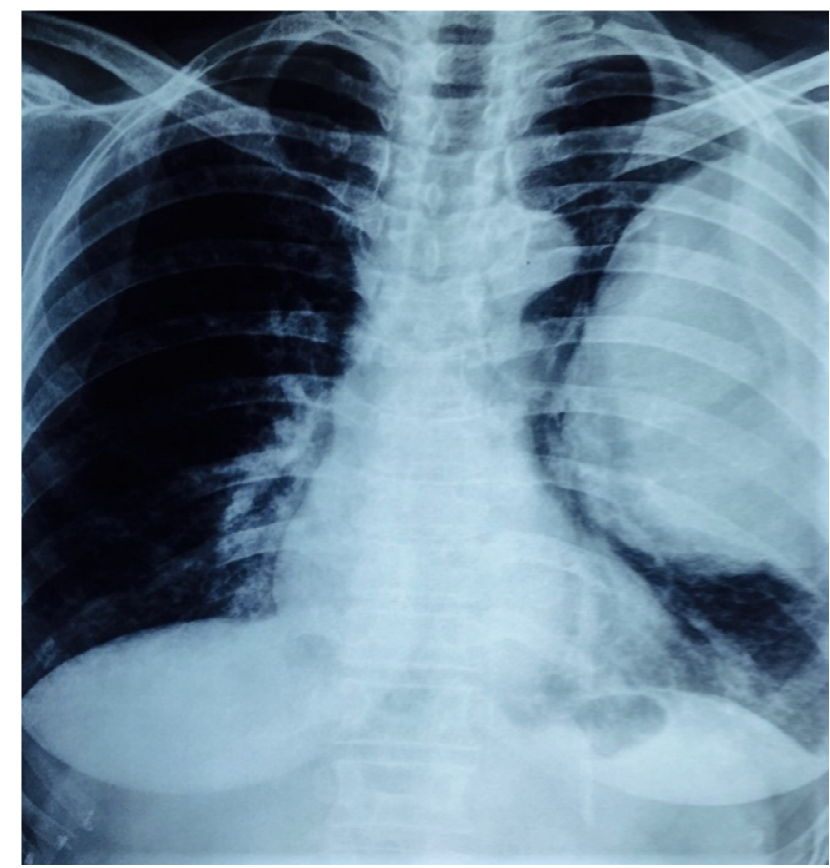

Figure I Chest X-ray showing left sided pleural effusion.

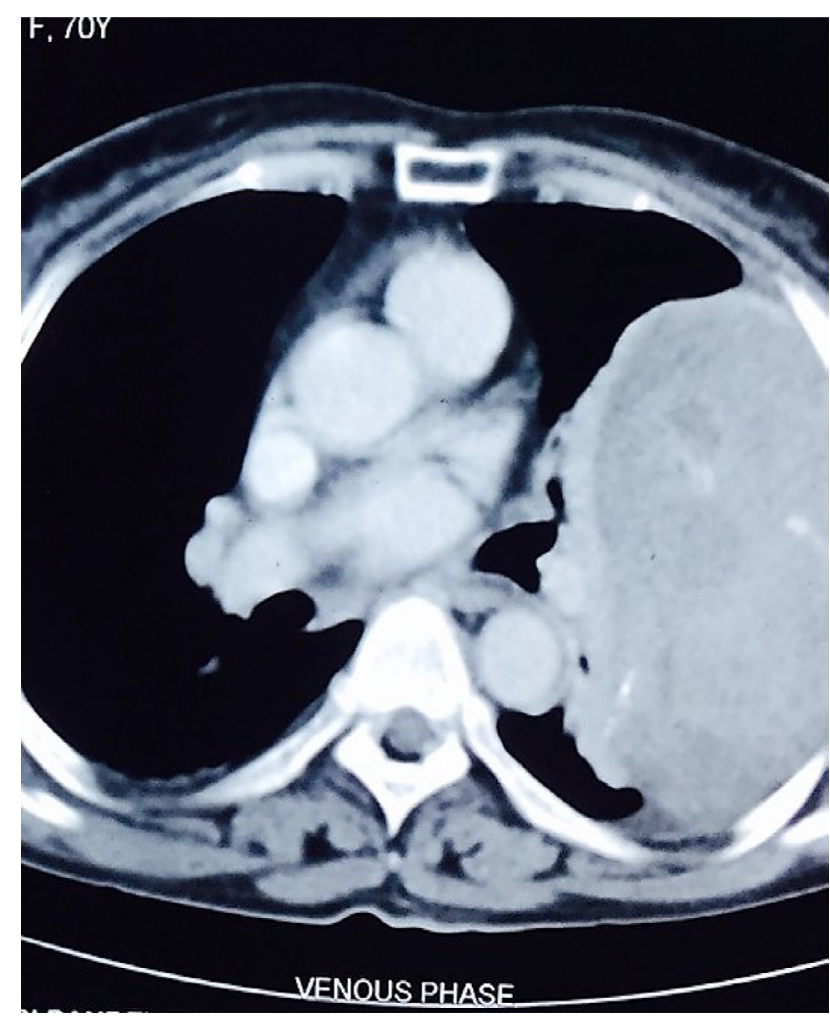

Figure 2 Computed tomography scan of the chest showing left sided lung mass.

The administration of any hypoglycemic agent was ruled out. The patient was clinically Whipple's triad positive suggesting true hypoglycemia. During hypoglycemia, the serum insulin level was below $3 \mathrm{mU} / \mathrm{L}$ (Ref: $3.0-25.0 \mathrm{mU} / \mathrm{L}$ ) and
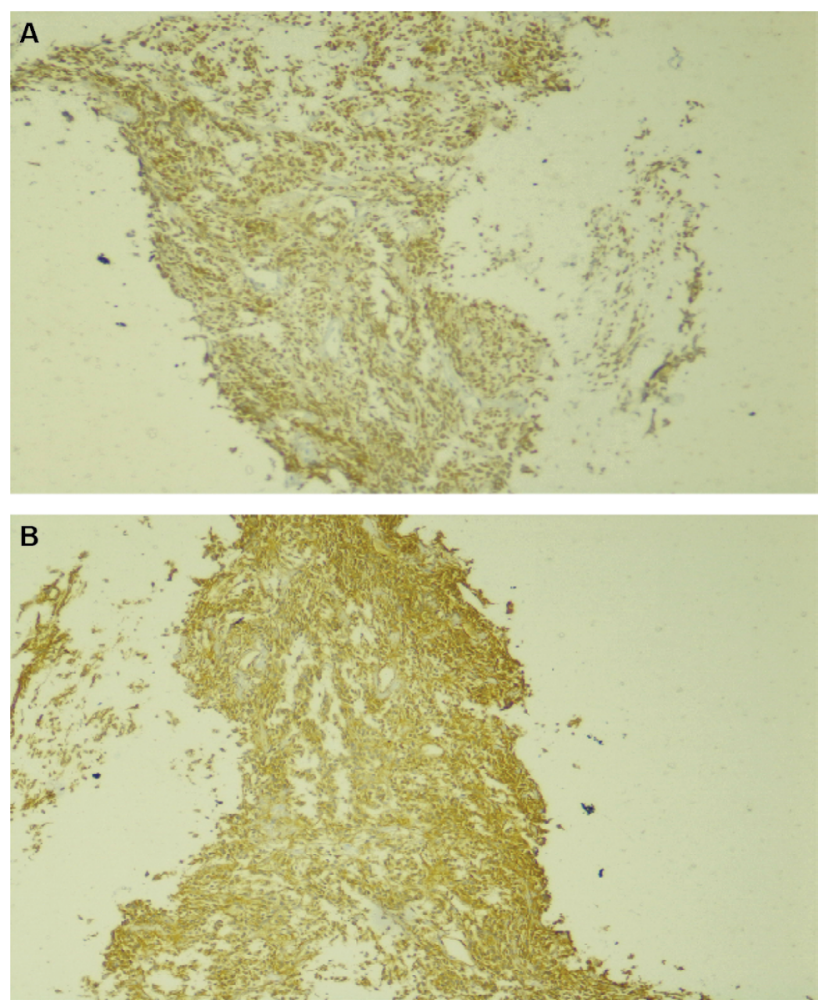

Figure 3 (A) An immunohistochemical stain for BCL-2 performed on the biopsy specimen. (B) An immunohistochemical stain for CD34 performed on the biopsy specimen.

serum c-peptide level was below $0.05 \mathrm{ng} / \mathrm{mL}$ (Ref: 0.81$3.85 \mathrm{ng} / \mathrm{mL}$ ). Anti-insulin antibody was absent. Investigation for insulin-like growth factor 2 (IGF-II) was not done because of nonavailability of the test. Subsequent surgical resection led to complete resolution of the symptoms. A left lateral thoracotomy was performed for resection of the pleural mass. (Figure 4) A large tumor originating over the surfaces of the left lower and middle lobe was found, and this was not invading fissure and lingula. The tumor was well circumscribed and encapsulated, measuring $12 \times 10 \times 8 \mathrm{~cm}$ in size. (Figure 5) True hypoglycemia, low insulin and c-peptide, and resolution of hypoglycemia after resection of a tumor confirmed solitary fibrous tumor (SFT) with Doege-Potter syndrome (DPS) as the etiology of hypoglycemia.

The patient has been under regular follow-up for the past 2 years and has no complaints and is currently not taking any medication.

\section{Discussion}

Hypoglycemia accompanying SFTP is specifically referred to as the DPS. ${ }^{1}$ The age at diagnosis is typically $38-79$ years. ${ }^{6}$ A large form of IGF-II, which is an incompletely processed molecule of IGF-II, is derived from the tumor and considered to cause hypoglycemia. ${ }^{2}$ Normally, IGF-II forms an inactive 


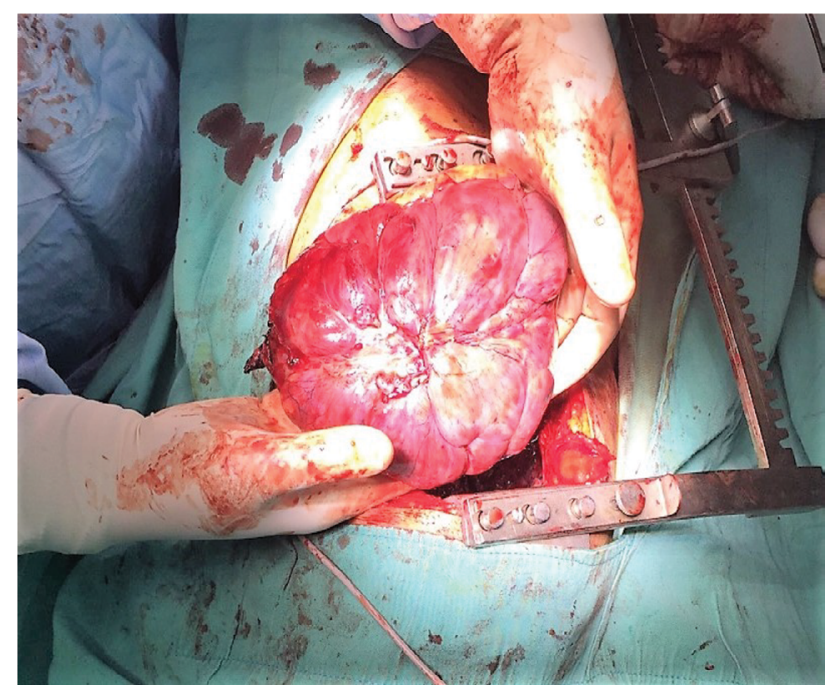

Figure 4 Surgical resection of tumor through left lateral thoracotomy approach.

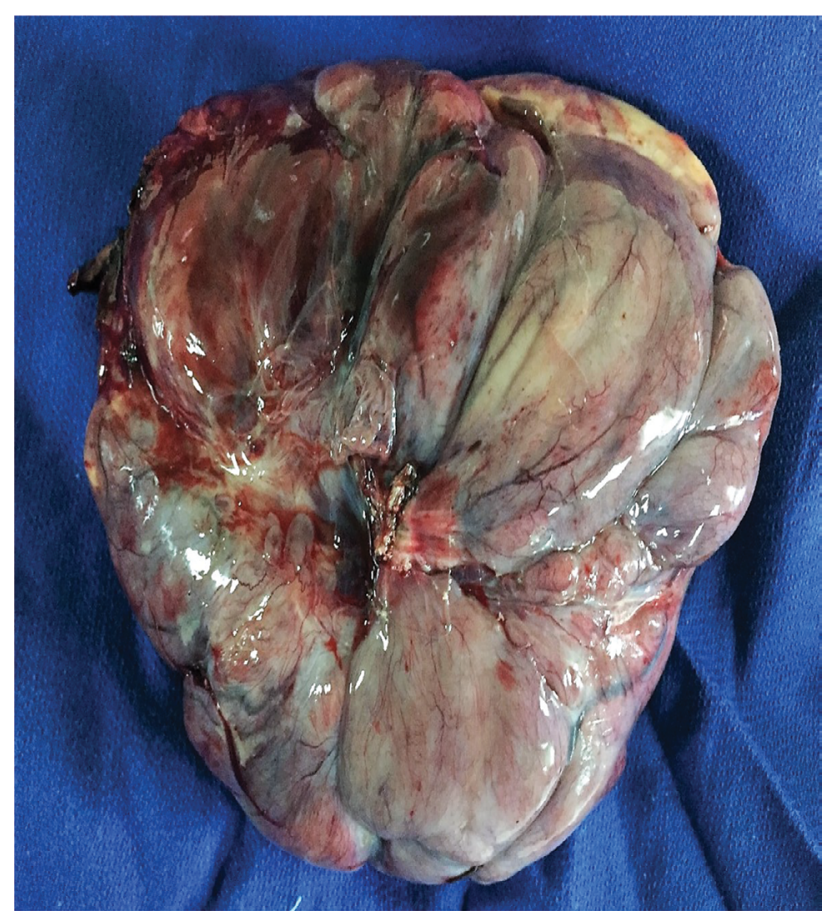

Figure 5 Gross specimen of the SFT of left lung which is well circumscribed, encapsulated, and measuring $12 \times 10 \times 8 \mathrm{~cm}$ in size.

Abbreviation: SFT, solitary fibrous tumor.

ternary complex with IGF-binding protein-3 and an acidlabile subunit. On the contrary, this large form of IGF-II, derived from tumor, fails to form a complex and binds to IGF-binding protein-2, in an abnormal binary complex that can cross capillary membranes and cause hypoglycemia. ${ }^{8}$ SFT cells have a markedly greater expression of IGF-II mRNA and a lesser expression of prohormone convertase $4 \mathrm{mRNA}$ compared to normal placental tissue. Prohormone convertase
4 is an endoprotease involved in processing precursor highmolecular-weight (HMW) IGF-II that cleaves pro-IGF-II to generate the mature IGF-II ${ }^{12}$ The unprocessed HMW IGF-II has significantly higher bioavailability in DPS compared to mature or processed IGF-II. ${ }^{11,13}$ Thus, hypoglycemia is caused by this unprocessed HMW IGF-II. Most SFTP associated with DPS is in the right lower hemithorax. ${ }^{3}$ SFTs can arise from a wide range of anatomic sites, both intrapleural or extrapleural. ${ }^{9}$ In this case, the tumor was intrapleural in the left hemithorax. Among the cases reported globally, 50\% are benign and 50\% have malignant transformation. ${ }^{6}$ In this case, histopathological examination confirmed the benign nature of the tumor. Definitive diagnosis of an SFT relies on histological identification of a spindle cell tumor with a distinctive fibroblastic morphology, arranged as areas of alternating cellularity and hypocellular collagenous stroma, as well as consistent CD34 expression. ${ }^{7}$ In trucut biopsy of the specimen taken from this case, diffuse proliferation of spindle shaped cells with blood vessels in between was seen. These spindle cells were mildly pleomorphic and had elongated cytoplasm with hyperchromatic nucleus. Mitotic figure was not observed, and there was no necrosis. BCL-2 and CD34 are positive in SFTs but chromogranin A and synaptophysin are positive in carcinoid tumors. Sensitivity of BCL-2 and CD34 to detect SFTs is $96.2 \%$ and $88.7 \%$, respectively. ${ }^{14}$ In this case, both BCL-2 and CD34 staining were positive. Investigations at the time of hypoglycemia in these patients reveal a high IGF-II: IGF-I ratio and low insulin concentration. ${ }^{7}$ Estimation of IGF-I and II could not be done in our case due to nonavailability of the test. Likewise, fluorescence in situ hybridization or quantitative polymerase chain reaction for mRNA and protein staining were not done due to financial constraint. Serum insulin level and serum c-peptide level were much lower during the period of hypoglycemia, suggesting true hypoglycemia. Hypoglycemia is rare in pleural SFT, occurring in approximately $5 \%$ of cases. ${ }^{10}$ Surgery is the first-line effective treatment for benign and malignant masses. ${ }^{4,5}$ Surgical resection in this case led to complete resolution of the symptoms. The patient has been under regular follow-up for the past 2 years and has no complaints. To our knowledge, this is the first case of SFTP associated with DPS reported from Nepal.

\section{Conclusion}

Tumor-induced hypoglycemia should be considered as the primary differential diagnosis in a patient with a known thoracic malignancy if accompanied by features suggestive of hypoglycemia. 


\section{Consent}

Written informed consent has been provided by the patient to have the case details and any accompanying images published.

\section{Disclosure}

The authors report no conflicts of interest in this work.

\section{References}

1. Kalebi AY, Hale MJ, Wong ML, Hoffman T, Murray J. Surgically cured hypoglycemia secondary to pleural solitary fibrous tumour: case report and update review on the Doege-Potter syndrome. J Cardiothorac Surg. 2009;4(1):45.

2. Daughaday WH, Kapadia M. Significance of abnormal serum binding of insulin-like growth factor II in the development of hypoglycemia in patients with non-islet-cell tumors. Proc Natl Acad Sci U S A. 1989;86(17):6778-6782.

3. England DM, Hochholzer L, McCarthy MJ. Localized benign and malignant fibrous tumors of the pleura: a clinicopathologic review of 223 cases. Am J Surg Pathol. 1989;13(8):640-658.

4. Gold JS, Antonescu CR, Hajdu C, et al. Clinicopathologic correlates of solitary fibrous tumors. Cancer. 2002;94(4):1057-1068.

5. Santos RS, Haddad R, Lima CE, et al. Patterns of recurrence and longterm survival after curative resection of localized fibrous tumors of the pleura. Clinical Lung Cancer. 2005;7(3):197-201.
6. Meng W, Zhu HH, Li H, Wang G, Wei D, Feng X. Solitary fibrous tumors of the pleura with Doege-Potter syndrome: a case report and three-decade review of the literature. BMC Res Notes. 2014;7(1):515.

7. Hajdu M, Singer S, Maki RG, Schwartz GK, Keohan ML, Antonescu CR. IGF2 over-expression in solitary fibrous tumours is independent of anatomical location and is related to loss of imprinting. J Pathol. 2010;221(3):300-307.

8. Zapf J. Role of insulin-like growth factor II and IGF binding proteins in extrapancreatic tumor hypoglycemia. Horm Res. 1994;42(1-2):20-26.

9. Takizawa I, Saito T, Kitamura Y, et al. Primary solitary fibrous tumor (SFT) in the retroperitoneum. Urol Oncol. 2008;26(3):254-259.

10. Zafar H, Takimoto CH, Weiss G. Doege-Potter syndrome. Med Oncol. 2003;20(4):403-407.

11. Tani Y, Tateno T, Izumiyama H, Doi M, Yoshimoto T, Hirata Y. Defective expression of prohormone convertase 4 and enhanced expression of insulin-like growth factor II by pleural solitary fibrous tumor causing hypoglycemia. Endocrine J. 2008;55(5):905-911.

12. Qiu Q, Basak A, Mbikay M, Tsang BK, Gruslin A. Role of pro-IGF-II processing by proprotein convertase 4 in human placental development. Proc Natl Acad Sci U S A. 2005;102(31):11047-11052.

13. Bond JJ, Meka S, Baxter RC. Binding characteristics of pro-insulinlike growth factor-II from cancer patients: binary and ternary complex formation with IGF binding proteins-1 to-6. J Endocrinol. 2000;165(2):253-260.

14. Han Y, Zhang Q, Yu X, et al. Immunohistochemical detection of STAT6, CD34, CD99 and BCL-2 for diagnosing solitary fibrous tumors/ hemangiopericytomas. Int J Clin Exp Pathol. 2015;8(10):13166-13175.
International Medical Case Reports Journal

\section{Publish your work in this journal}

The International Medical Case Reports Journal is an international, peer-reviewed open-access journal publishing original case reports from all medical specialties. Previously unpublished medical posters are also accepted relating to any area of clinical or preclinical science. Submissions should not normally exceed 2,000 words or

\section{Dovepress}

4 published pages including figures, diagrams and references. The manuscript management system is completely online and includes a very quick and fair peer-review system, which is all easy to use. Visit $\mathrm{http}: / /$ www.dovepress.com/testimonials.php to read real quotes from published authors.

Submit your manuscript here: https://www.dovepress.com/international-medical-case-reports-journal-journal 